\title{
BOTOX - A NEW WEAPON IN A DENTIST'S ARSENAL
}

\author{
Mitasha Sachdeva ${ }^{1}$, Vinay Dua ${ }^{2}$, Puneet Gupta ${ }^{3}$, Gaurav Ahuja ${ }^{4}$ \\ ${ }^{1}$ P.G student, Department of Orthodontics and Dentofacial Orthopaedics, MM College of Dental Sciences and Research, Haryana, India \\ ${ }^{2}$ Professor and Head, Department of Orthodontics and Dentofacial Orthopaedics, MM College of Dental Sciences and Research, Haryana, India \\ ${ }^{3}$ Senior lecturer, Department of Orthodontics and Dentofacial Orthopaedics, MM College of Dental Sciences and Research, Haryana, India \\ ${ }^{4}$ P.G student, Department of Orthodontics and Dentofacial Orthopaedics, MM College of Dental Sciences and Research, Haryana, India
}

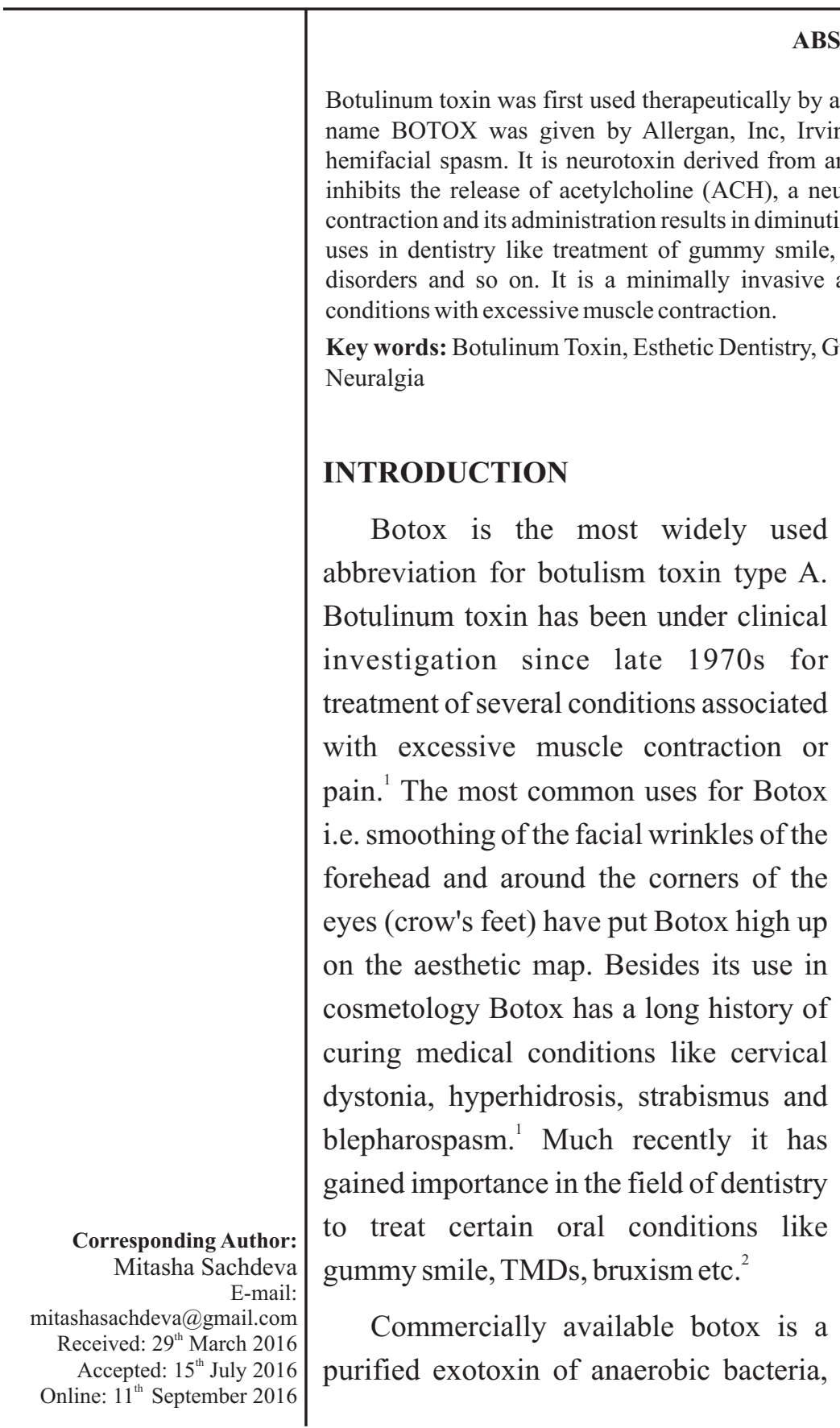

Clostridium botulinum. This same neurotoxin is the cause of the rare but fatal illness, botulism. Seven types of botulinum toxin have been isolated A, B, C1, D, E, F, G. Out of these only two type A and B are commercially available. Three forms of botulinum toxin type A (Botox, Dysport and Xeomin) and one form of botulinum toxin type $B$ (MyoBloc) are available for various cosmetic and medical procedures. ${ }^{2}$

\section{How does it work?}

The toxin targets the axon terminals which incorporate it by endocytosis. Once inside the neuron, it cleaves the synaptosomal associated protein (SNAP25) [a protein from the soluble $\mathrm{N}$ ethylmaleimide-sensitive factor attachment receptor (SNARE) family involved in vesicle fusion and mediating release of neurotransmitter - 
acetylcholine, from axon endings]. Cleavage of the SNARE proteins inhibits release of acetylcholine which in turn blocks the nerve impulses thereby causing the muscle paralysis. ${ }^{3}$ Figure $1 .^{4}$

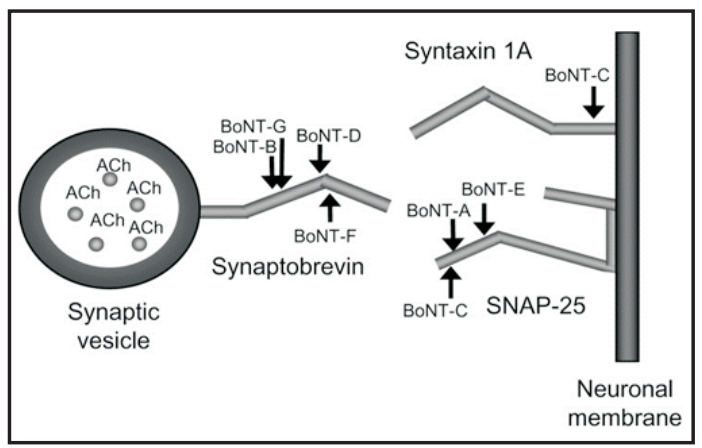

Figure 1: Shows that botulinum neurotoxin serotypes cleave peptide bonds at specific sites on 3 proteins i.e. synaptobrevin, syntaxin and SNAP (synaptosomal-associated protein)-25.

\section{Using Botox}

The vial of botox can contain 50 units, 100 units or 200 units of freeze dried powder clumps of toxin. ${ }^{5}$ Before injecting, dilution with $0.9 \%$ sodium chloride (saline) is done. A 100 unit vial is diluted with $2.5 \mathrm{ml}$ saline. The resultant dose per $0.1 \mathrm{ml}$ would be 4 units. A $1 \mathrm{cc} / 1 \mathrm{ml}$ insulin syringe is used for injecting botox. It is injected intramuscularly. Botox is easily contaminated by bubbling or agitation so the dilutent is slowly injected into the vial and if the vacuum does not pull the dilutent, the vial is discarded. Botox should be administered within 24 hours after reconstitution. During this time period, reconstituted Botox should be stored in a refrigerator $\left(2^{\circ}\right.$ to $\left.8^{\circ} \mathrm{C}\right)$. The effect of botox lasts for 3-6 months. It is a reversible treatment, the muscles return to the normal functioning as soon as the effect wears off. Re injection can be done after a 3 month interval to minimize the risk of antibody formation to the protein. ${ }^{6,7}$

\section{Dental applications of Botox:}

It can be used to treat:-

- Gummy smile
- TMDs

- Mandibular spasms/ Oromandibular Dystonia

- Masticatory muscle hypertrophy

- Bruxism

- Sialorrhea

- Headache, migraine, trigeminal neuralgia

- Myofacial pain

- Orthodontic relapse

\section{Gummy Smile}

The excessive display of the gingival tissue in maxilla upon smiling is called as 'gummy smile'. ' Some people exhibiting this kind of smile tend to feel awkward and uneasy with their appearance and some are even psychologically affected. A dentist should always aim at providing a beautiful smile and not just beautiful teeth. Gummy smile due to hyperfunctional upper lip elevator muscles can be effectively treated using Botox.

According to a pilot study done by Mario Polo1 on five patients exhibiting excessive gingival display, 1.25 $\mathrm{U}$ botox was injected into both right and left levator labii superioris and levator labii superioris alaeque nasi muscles with an additional $1.25 \mathrm{U}$ over the overlap areas of levator labii superioris and zygomaticus minor muscles. After two weeks there was effective increase in the lip length of all five patients and they were pleased with the results.

Another study by Hwang WS et al. ${ }^{8}$ found a safe and reproducible point for the injection of the toxin. This point was called the Yonsei point (Figure-2) ${ }^{5}$ and it is located at the centre of triangle formed by levator labii superioris, levator labii superioris alaeque nasi and zygomaticus minor muscles. The authors recommended a dose of around $5 \mathrm{U}$ appropriate for facial muscles. 


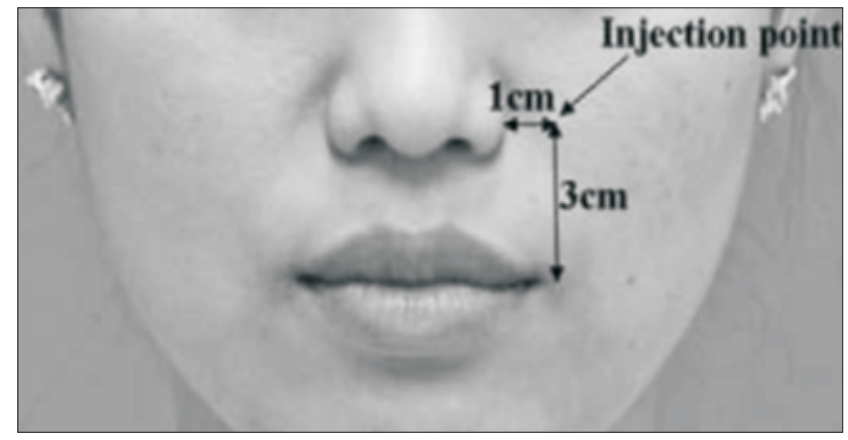

Figure 3: Yonsei point ${ }^{5}$

\section{TMDs}

Problems associated with the jaw and muscles of mastication are referred as temporomandibular disorders. TMDs include problems related to the muscles (myofascial) or to the joint (arthrogenic). Etiology includes injury to the jaw, clenching teeth tightly which causes pressure on the jaw, arthritis of the joint. Symptoms manifest as toothaches, headaches, neck aches, tinnitus, ear aches and general facial pain. TMD cases present with one or more trigger points on the facial muscles affected. ${ }^{9}$ Many treatment methods are available to treat TMDs ( pain medications, muscle relaxants, psychological therapy, intraoral appliances to correct TMD caused by excessive biting forces, surgery). Amongst various treatment modalities botox is the new insight for treating TMDs associated with the hyperfunctional muscles. Since botox causes muscles to paralyze, the clenching effect can be reduced thereby relaxing the muscle function. The temporalis and masseter muscles are most commonly affected and injected with the toxin. 10-25 $\mathrm{U}$ of toxin is injected for temporalis muscle, 25-50 U for masseter muscle and 7.5-10 U for lateral pterygoids.10 Botox significantly reduces the intensity, frequency and duration of recurrent pain if injected properly.

\section{Mandibular Spasms/ Oromandibular Dystonia (OMD)}

OMD is characterized by involuntary spasm of the muscles that move the jaw and mouth producing forceful contractions of the face, jaw or tongue. Due to these involuntary contractions, mouth and tongue are pulled into different positions affecting chewing and speech. Mandibular spasms usually result in restricted mouth opening therby limiting the maintaince of basic oral hygiene. Botox lessens the effects of these muscle contractions and spasms which improves the function, speech and mouth opening. 2,6,9,11,12

\section{Masticatory muscle hypertrophy/masseteric hypertrophy}

Characterized by an increase in the volume of the muscle mass. It has various causative factors like bruxism, TMDs, malocclusion. Often it is associated with a soft swelling near the angle of the mouth which can be painful. ${ }^{13}$ Main concern in patients with masseteric hypertrophy is the cosmetic disfigurement of the face. ${ }^{14}$ Until now this condition was treated by surgical resection of the masseter muscle. Use of botox therapy has shown to be a successful and less invasive treatment modality. A study was done by Choe SW et al. ${ }^{15}$ to observe effects of botulinum toxin type $\mathrm{A}$ in treatment of massetric hypertrophy with different doses 10U, 20U and 30U. They concluded that the adequate dose of botulinum toxin type A for treatment of masseteric muscle hypertrophy should be above 20 $\mathrm{U}$. The effect of botulinum toxin type A is maintained for at least 9 months as the treatment of masseteric muscle hypertrophy.

\section{Bruxism}

It is a condition in which there is excessive grinding or clenching of teeth. Teeth grinding can be caused by stress and anxiety, it often manifests during sleep. Mouthguards and nightguards can be used effectively to protect teeth against clenching damage but they do not stop the clenching from happening. Treatment using botox aids in limiting the over function of the muscles responsible for chewing, mainly the temporalis and massester. A study was done by Tan EK and Jankovic $\mathrm{J}^{16}$ on 18 subjects having severe bruxism. They treated these patients with botulinum toxin of 25 - 
$100 \mathrm{U}$ and concluded that it is a safe and effective treatment for people with severe bruxism, particularly those with associated movement disorders.

\section{Sialorrhea}

Hypersalivation or sialorrhea is term given to excessive production of saliva. Etiology includes neurological disorders like Parkinson's disease, oral ulcers, oral infections, liver diseases, certain medications. Botox used in treatment of sialorrhea aims to inhibit stimulation of cholinergic receptors. It is injected into parotid and submaxillary salivary glands. In a study done by Gomez-Caravaca $\mathrm{MT}^{17}$ et al, they injected botox in parotid gland of 41patients suffering from Parkinson's disease in order to treat sialorrhea. Mean dose of $22.17 \pm 8.76$ units was administered. They concluded that adverse effects were mild and infrequent hence botox can be administered safely and efficiently in patients with Parkinson's disease. Another study by Fuster Torres MA ${ }^{18}$ reviewed salivary gland application of botulinum toxin for treatment of sialorrhea. According to their review different authors have recommended different doses of Botox ranging from 10-100U. Also a reduction was observed in the production of saliva following these injections, and the duration of the therapeutic effect was 1.5-6 months.

\section{Myofacial pain}

It is characterized by chronic pain in the fascia. There are various myofacial trigger points which set off pain. There is localized tenderness, referred pain to distant sites, and hardening of the affected muscle upon trigger point palpation. Botox is effective in relaxing the muscles. ${ }^{19,20}$

\section{Headache, Migraine, Trigeminal Neuralgia}

Chronic migraine treatment can help ease symptoms but not all patients respond well to pain medicines. Two possibilities have been put forward as to how botox works in treating migraine. One theory is that it causes muscles to paralyze which trigger migraine and the other is that it blocks the protein(substance $\mathrm{P}$ ) that carries the message of pain to the brain.

Trigeminal neuralgia (TN) is a painful disorder of the trigeminal nerve characterized by paroxysmal attacks of severe, electric shock-like pain typically present on one side of the face. ${ }^{21}$ Various treatment modalities for trigeminal neuralgia include medicinal management, peripheral nerve injection of local anesthetic or alcohol, peripheral neurectomies, alcohol injection of trigeminal ganglion, and intracranial neurosurgical procedures. The less invasive technique i.e botox produces an anti inflammatory action by blocking an inflammatory neuropeptide calcitonin gene-related peptide (CGRP). ${ }^{22}$ Another mechanism by which botox leads to reduction in pain is by decreasing the release of glutamate peripherally (glutamate is responsible for inflammation, pain and edema). ${ }^{23}$ Case reports ${ }^{24,25}$ have been published in which the patients suffering from trigeminal neuralgia are treated with botox. Complete pain relief for about 5 months was obtained in both the case reports.

\section{Orthodontic relapse}

It is a well-known fact that muscles play a very important role in determining the placement of teeth. ${ }^{2}$ After orthodontic therapy, once the teeth are set, dentists tend to forget about the role of muscles and hence relapse has been a continual problem. The most common muscle which is responsible for relapse is the hyperactive metalis.' Botox reduces the muscle contraction intensity and with time the muscle can be trained to function normally.

\section{Other uses of BOTOX in head and neck region}

1. Facial wrinkles - treatment of frown line (glabellar lines), eyebrow lift, "crow's feet", perioral lines (smoker's lines). ${ }^{26}$

2. Drooping of corners of mouth - caused by hyperactivity of depressor anguli oris. Injection on the trajectory of nasolabial fold to the jaw line can treat it. ${ }^{27}$ 
3. Facial nerve palsy - often accompanies hyperlacrimation (crocodile tears) associated with salivation due to the connection between secretomotor fibers of salivary gland to lacrimal gland. Injection of botox into lacrimal gland has been used to manage this condition. ${ }^{26}$

4. Implantology - stresses due to functional and parafunctional habits cause failure of the implant as they disturb the process of osseointegration. Botox relaxes the muscles and cause unrestricted bone formation around the implant. ${ }^{28}$

5. In patients who have been edentuluous for a long period of time face the difficulty in getting used to a new set of dentures due to irregular and uncoordinated muscle activity. Botox can be helpful for such patients. ${ }^{2,26}$

6. Maxillofacial trauma - Botox has been useful in treating injuries affecting the bones in the maxillofacial region including maxilla, mandible, zygoma, nasal bone, and orbital bone.26 Higher doses of Botox may potentially be used as a pharmaceutical splint during management of fractured facial bone. Also it is effective in the correction of posttraumatic anterior open bite by successful injection in anterior belly of digastrics. ${ }^{29}$

7. Cancer care-after reconstructive surgery has been done in patients with cancer, Botox can be used to treat spastic pain in these patients and also to treat synkinesis. $^{30,31}$

\section{Advantages of Botox}

Botox is safe, minimally invasive, reversible treatment modality and can serve as a substitute for surgical procedures. ${ }^{2,6}$ In cases of hyperactive musculature e.g. hyperactive lip musculature botox application is useful as surgical procedures to correct gummy smile have undesirable side effects such as scar formation and also tendency towards relapse is more. In a study conducted by Woo-Sang Hwanga et al in 2009, asymmetric smile (resulting from difference in muscle activity and not distribution) was corrected by using Botox injections. ${ }^{8}$ In cases of patients with maxillofacial fracture fixation hyperactive masticatory muscles prevent callus formation, Botox injections not only provide a stable environment for fracture healing but also when given before plating, fewer number of miniplate insertion is required for stabilization. ${ }^{32,33}$ Effects of Botox are not permanent and last upto 3-6 months. ${ }^{2}$

Contraindication to Botox therapy ${ }^{6,9}$

1. Psychologically unstable patients

2. Patients with neuromuscular disorders (myaesthnia gravis, Lambert-Eaton syndrome)

3. Pregnant or lactating women

4. Allergy or sensitivity to the toxin components

5. Presence of inflammation or infection at the site of injection

6. Patients on medications like aminoglycosides, calcium channel blockers, quinine

\section{Adverse effects ${ }^{2,5,6,9}$}

1. Related to injection site - burning, stinging, edema, erythema around the injection site

2. Botox can cause temporary weakening of the muscles injected

3. When used for a long time, can cause atrophy (reversible) of muscles injected.

4. Rare side effects include numbness, paresthesia, twitching, mild nausea and myalgias.

\section{CONCLUSION}

Botox has been demonstrated to have significant role in management of various dentofacial disorders. It is a minimally invasive technique and can be easily administered by dental practitioners. Patients should be motivated to accept this therapy as it is a safe and conservative approach that can expand our therapeutic options for the benefit of the patients. 


\section{REFERENCES:}

1. Polo M. Botulinum toxin type $\mathrm{A}$ in treatment of excessive gingival display. Am J Orthod Dentofacial Orthop 2005;127:214-218.

2. Nayyar P, Kumar P, Nayyar PV, Singh A. BOTOX: Broadening the Horizon of Dentistry. JCDR. 2014;8(12):25-29.

3. Bing Li, Norton P, Butler M, Burnett JC, Moi D. Small molecule inhibitors as countermeasures for botulinum neurotoxin intoxication. Molecules 2011;16(1): 202-220.

4. Barr JR, Moura H, Boyer AE, Woolfitt AR, Kalb SR, Pavlopoulos A. Botulinum Neurotoxin Detection and Differentiation by Mass Spectrometry. Emerg Infect Dis 2005;11(10):1578-1583.

5. Patel D, Mehta F, Trivedi R, Thakkar S, Suthar J. Botulinum Toxin and Gummy Smile- A Review. IOSR-JDMS 2013;4(1):1-5.

6. Rao LB, Sangur R, Pradeep S. Application of Botulinum toxin Type A: An arsenal in dentistry. IJDR 2011;22(3):440-445.

7. Dolly O. Synaptic transmissions: inhibition of neurotransmitter releaseby botulinum toxins. Headache 2003;43:S16-24.

8. Hwang WS, Hur M, Hu KS, Song WC, Koh KS, Baik HS. Surface Anatomy of the Lip Elevator Muscles for the Treatment of Gummy Smile Using Botulinum Toxin. Angle Orthod 2009;79:70-77.

9. Grover S, Malik V, Kaushik A, Yadav P. A future perspective of Botox in dentofacial region. J Pharm Biomed Sci 2014;4(6):525-531.

10. Song PC, Schwartz J, Blitzer A. The emerging role of botulinum toxin in treatment of temporomandibular disorders. Oral diseases 2007; 13:253-260.

11. Delnooz C, Bart P.C. Current and future medical treatment in primary dystonia. Ther Adv Neurol Disord 2012; 5(4): 221-240.

12. Mendes RA, Upton LG. Management of dystonia of the lateral pterygoid muscle with botulinum toxin A. $\mathrm{Br} \mathrm{J}$ Oral Maxillofac Surg 2009;47:481-483.

13. Fedorowicz Z, Zuuren EJ, Schoones J. Botulinum toxin for masseter hypertrophy. Cochrane Database Syst Rev 2013 ;9: CD007510.

14. Al-Muharraqi Ma, Fedorowicz Z, Al Bareeq J, Al Bareeq R, Nasser M. Botulinum toxin for masseter hypertrophy. Cochrane Database Syst Rev 2009 Jan 21; 1: CD007510.

15. Choe SW, Choe WI, Lee CK, Seo SJ. Effects of botulinum toxin type A on contouring lower face. Dermatol Surg 2005;31(5):502-507.

16. Tan EK, Jankovic J. Treating severe bruxism with botulinum toxin. JAm Dent Assoc 2000;131(2):211-6.

17. Gomez-Caravaca MT, Caceres-Redondo MT, HuertasFernández I, Vargas-Gonzalez L, Carrillo F, Carballo M, Mir P. The use of botulinum toxin in the treatment of sialorrhea in parkinsonian disorders. Neurol Sci. 2015;36(2):275-279.

18. Fuster Torres MA, Berini Aytes L, Gay Escoda C. Salivary gland application of botulinum toxin for the treatment of sialorrhea. Med Oral Patol Oral Cir Bucal. 2007;12(7):511517.

19. Sunil Dutt C, Ramnani P, Thakur D, Pandit M. Botulinum toxin in the treatment of muscle specific Oro-facial pain: a literature review. J Maxillofac Oral Surg. 2015 ;14(2):171-175.

20. Fallah HM, Currimbhoy S. Use of Botulinum Toxin A for Treatment of Myofascial Pain and Dysfunction. J Oral Maxillofac Surg. 2012;70(5):1243-1245.

21. Verma G. Role of botulinum toxin type A (BTX-A) in management of trigeminal neuralgia. Pain research and treatment 2013(12):831094.

22. Durham PL, Cady R, Blumenfeld AJ. Regulation of calcitonin gene-related peptide secretion from trigeminal nerve cells by botulinum toxin type A: implications for migraine therapy. Headache 2004;44(1):35-43.

23. U Turk, S. Ilhan, R. Alp, and H. Sur. Botulinum toxin and intractable trigeminal neuralgia. Clinical Neuropharmacology 2005;28(4):161-162.

24. Allam N, Brasil-Neto JP, Brown G, Tomaz C. Injections of botulinum toxin type A produce pain alleviation in intractable trigeminal neuralgia. Clin J Pain. 2005;21(2):182-184.

25. Ngeow WC, Nair R. Injection of botulinum toxin type A (BOTOX) into trigger zone of trigeminal neuralgia as a means to control pain. Oral Surg Oral Med Oral Pathol Oral Radiol Endod. 2010;109(3):47-50.

26. Srivastava S, Kharbanda S, Pal U.S and Shah V. Applications of botulinum toxin in dentistry: A comprehensive review. Natl J Maxillofac Surg. 2015 Jul-Dec; 6(2): 152-159.

27. Choi YJ, Kim JS, Gil YC, Phetudom T, Kim HJ, Tansatit T. Anatomical considerations regarding the location and boundary of the depressor anguli oris muscle with reference to botulinum toxin injection. Plast Reconstr Surg. 2014;134:917-21.

28. Ihde S. Prophylactic use of botulinum toxin in dental 
implantology. CMF Implement Dir. 2007;1:29-34.

29. Seok H, Park YT, Kim SG, Park YW. Correction of posttraumatic anterior open bite by injection of botulinum toxin type A into the anterior belly of the digastric muscle: Case report. J Korean Assoc Oral Maxillofac Surg. 2013;39:188-92.

30. On AY, Kirazli Y, Kismali B, Aksit R. Mechanisms of action of phenol block and botulinus toxin Type A in relieving spasticity: Electrophysiologic investigation and follow-up. Am J Phys Med Rehabil.1999;78:344-9.
31. Laskawi R, Ellies M. The role of botulinum toxin in the management of head and neck cancer patients. Curr Opin Otolaryngol Head Neck Surg. 2007;15:112-6.

32. Govindaraju P, Sadand S, Venugopal S, Ramaiah S.K , Mathew M, Parashuram S.C. Botulinum toxin-An Innovative Treatment Approach in Dental Practice. J Young Pharm, 2016; 8(1): $2-5$

33. Kayikvioglu A, Erk Y, Mavilli E, Vargel I, Ozgur F. Botulinium toxin in the treatment of zygomatic fracture. PlastReconstr Surg. 2003;111:341-6. 